\title{
Desired Teacher Education Graduate Attributes vis-a-vis Hiring-Related Requirements of Employers
}

\author{
Jennifer P. Santillan ${ }^{1}$, Jonar T. Martin ${ }^{2, *}$, Elvira S. Balinas ${ }^{3}$ \\ ${ }^{1}$ Office of the Vice President for Academic Affairs and College of Education, Angeles University Foundation, Philippines \\ ${ }^{2}$ College of Education, Pampanga State Agricultural University, Philippines \\ ${ }^{3}$ Graduate School, Angeles University Foundation, Philippines
}

Received January 14, 2020; Revised February 27, 2020; Accepted March 12, 2020

Copyright $\bigcirc 2020$ by authors, all rights reserved. Authors agree that this article remains permanently open access under the terms of the Creative Commons Attribution License 4.0 International License

\begin{abstract}
Outcomes-based education (OBE) mandates higher education institutions (HEIs) to identify expectations and formulate institutional learning outcomes (ILOs) or graduate attributes (GAs) which distinguish their products from the rest. These ILOs or GAs are qualities, skills, and understanding which students must develop and possess during their time with the institution and carry and apply as professionals. Among teacher education (TE) graduates, an HEI hopes to see outstanding instructional performance which is crucial to the latter's students' progress. Schools which screen teacher-applicants therefore want to hire and keep those who possess commendable instructional performance and show ideal characteristics. Faced with the challenges of implementing the new TE curriculum approved in 2017, the investigators wanted to know the requirements of school-employers, if these requirements match the newly formed ILOs or GAs of Angeles University Foundation (AUF), and if AUF TE graduates manifest the requirements and the GAs at work. They interviewed top employers of the TE graduates of AUF as respondents through purposive sampling. Employer-participants involved in the hiring process identified qualifications, work-related characteristics, demands and expectations which are classified as knowledge, skills, values and described the TE graduates of AUF. Results show that the hiring-related requirements are aligned with the ILOs or GA of AUF while some are actually manifested by its TE graduates who practice the profession. Results have interesting implications for the training of pre-service teachers, the formation of GA, and the desires of employers especially in the Philippine context.
\end{abstract}

Keywords Graduate Attribute, Teacher Education, Outcomes-Based Education

\section{Introduction}

Teacher education (TE) is one of the priority degree programs identified by the Commission on Higher Education (CHED) and Department of Labor and Emp loy ment (DOLE) [1] of the Republic of the Philippines. Aside from the profession being lucrative, the working condition of teachers has also been given much attention and consideration. For example, Republic Act 4670 or the Magna Carta for Public School Teachers limits the actual classroom teaching of public school teachers to six hours at most "except when undertaking academic activities that require presence outside the school premises".

As a result, more Filipinos are taking up TE considering that salaries of public school teachers have also remarkably improved. To be specific, from academic year (AY) 2010-2011 to 2015-2016, the average annual increase in enrollment at teacher education institutions (TEIs) was higher at 11 percent [2]. Bacani [1] added that takers of priority courses, such as TE, get financial support from the government, have higher chances of employment, and may contribute to national development. National development also covers global competitiveness; hence, TE graduates can work locally or abroad especially with the growing demand for them in the international scene.

However, to enjoy the benefits of being a teacher in the Philippines and overseas, one must develop and possess the necessary knowledge, skills, and values (KSVs) during his/her tertiary education [3,4]. Universities offering teacher education, therefore, prepare their students well by aspiring for graduate attributes (GAs) which are responsive to the demands of the discipline and the potential emp loyers across the globe. Particularly, universities align their graduate attributes which are KSVs with the goals of business, government and education [3]. In particular, Albalooshi [5] proposed attributes for undergraduate 
programs based on the above mentioned standards and compared the said attributes with Bahrain Qualifications Framework and pointed out parallelism.

Recognizing the various national and global fra meworks such as the K to 12 reform, Association of Southeast Asian Nations (ASEAN) integration, globalization, and the changing characteristics of the $21^{\text {st }}$ century learners, the Department of Education-Teacher Education Council led the rethinking and improvement of the National Competency-Based Teacher Standards (NCBTS) which gave birth to the Philippine Professional Standards for Teachers or PPST [15]. PPST articulates what constitutes teacher quality considering the $\mathrm{K}$ to 12 reform in basic education through well-defined domains, career stages, strands, and indicators that provide measures of professional learning, competent practice, and effective engagement. The PPST has seven domains which are content knowledge and pedagogy, learning environment, diversity of learners, curriculum and planning, assessment and reporting, community linkages and professional engagement, and personal growth and professional development. It has four career stages starting from beginning to distinguished teachers, which articulate developmental progression as teachers develop, refine their practice and respond to the complexities of educational reforms. Moreover, there are 37 strands corresponding to one indicator per career stage. The PPST has been noted to be highly comparable to New South Wales Institute of Teachers Professional Teaching Standards and Australian Professional Standards for Teachers in terms of lexicon.

The Department of Education (DepEd) has been using adopting and implementing the PPST as made official by its Depart ment Order 42, s. 2017. PPST now serves as basis for all learning and development programs for teachers. On the other hand, TEIs use the PPST as guide in honing their pre-service teachers by ensuring that the 37 beginning teacher indicators are addressed in the curriculum.

Angeles University Foundation (AUF), a non-stock, non-profit autonomous institution in Central Luzon, has seen and responded to the need to formulate its graduate attributes in the advent of outcomes-based education (OBE) as mandated by the CHED Memorandum Order 46 series of 2012. A UF is institutionally accredited by the Federation of Accrediting Agencies in the Philippines or FAAP and ISO 9001:2015-certified institution. Its institutional learning outcomes (ILOs) or GAs formed in 2017 are values-oriented, socially and ethically responsible, professionally competent, critical and creative thinker, lifelong learner, and globally oriented. Each comes with four descriptions. All of which are responsive to national and international needs.

More specifically, AUF College of Education (AUF CED) is a Center of Excellence for Teacher Education and has elementary and secondary programs as level IV accredited. In 2017, the College has started aligning its course syllabi with the GAs of the university but has acknowledged several concerns. First among the concerns is on how to measure if the attributes are achieved. Sproken-Smith et al. [6] suggested that evaluation and monitoring may be via periodic review, graduate opinion surveys, and alumni and employer surveys.

\section{Objectives}

The researchers particularly planned and completed this study to know if the TE graduates possess the GAs, using the lens of their employers. Specifically, they wanted to know the hiring requirements (i.e., qualifications, work-re lated characteristics, de mands, and e xpectations) of employers, if these require ments align with the AUF GAs, and if the graduates of AUF possess the requirements and the GAs as professionals.

\section{Materials and Methods}

This study is a descriptive research aiming to describe hiring-related requirements of employers and their align ment with AUF graduate attributes. The study lasted for three months. The researchers prepared a teacher-made questionnaire with nine questions. The first part of which requires demographic information from the respondents while the second part contains open-ended questions. The decision to use questionnaire is based on the study of Awofala, Olabiyi, Ogunleye, Udeani, and Fatade [7].

The researches then used purposive sampling to name its top three employers based on the number of employed alu mni in the last five AYs (i.e., 2012 to 2017) to avoid recall bias. The top employers are Department of Education or DepEd (Angeles City) representing the government sector and two private schools. All part icipants signed an informed consent.

All three employers offer basic education, have employed AUF CED alumni and are considered as stakeholders or those who may objectively assess if the attributes are evident among students and graduates [4]. Fifteen respondents representing the three employer-groups participated. Ten are subject area coordinators (i.e., English, Math, Science, and Social Studies) while three are education program supervisors (EPS). One is a human resource officer and another is an academic coordinator. These persons are all involved as evaluators in the hiring process with zero to 10 years of experience in their post. Those initially were identified as respondents but failed to meet the requirements of being involved in the hiring process and having worked with AUF graduates were excluded as participants.

The analysis of the data was done in two ways. The researchers analyzed the written data qualitatively and used descriptive statistics, particularly frequency, to quantify and present them. The second analysis is qualitatively using codes and noting similarities or use of synonyms. 


\section{Results}

Table 1 categorizes the hiring qualifications into knowledge, skills, values, and others. Topping the categories is knowledge. The most preferred knowledge is having mastery of subject matter while being strategic in teaching and being a good classroom manager come second. Next in the list are possessing specialized training and skills and being good in the art of questioning. Among the skills, being a good communicator with stakeholders scored the highest while employers identified the values determined, persistent, eager to work, loyal, confidence, creative, resourceful, fle xib le, and profes sional. Emp loyers also named looking pleasant, coming from a good school, having teaching experience, and having earned good grades as the other qualifications they look for among teacher-applicants.

Table 1. Hiring Qualifications

\begin{tabular}{|l|l|}
\hline Knowledge & Frequency \\
\hline Mastery of subject matter & 5 \\
\hline Strategic in teaching & 4 \\
\hline Good classroom manager & 4 \\
\hline Possesses specialized training and skills & 3 \\
\hline Good in the art of questioning & 3 \\
\hline Knowledgeable on content & 2 \\
\hline LET eligible & 2 \\
\hline Is learner-centered & 1 \\
\hline Can do disciplinary integration & 1 \\
\hline Skills & Frequency \\
\hline Good communicators with stakeholders & 13 \\
\hline Skillful in managing and planning teaching & 2 \\
\hline Computer literate & 1 \\
\hline Values & Frequency \\
\hline $\begin{array}{l}\text { Value laden (determined, persistent,eager to } \\
\text { work, } \\
\text { resourceful, flexible, professional) }\end{array}$ & 10 \\
\hline Others & Frequency \\
\hline Looking pleasant & 4 \\
\hline Coming from a good school & 2 \\
\hline Having teaching experience & 2 \\
\hline Earning good grades & 1 \\
\hline creatidence, & 13 \\
\hline
\end{tabular}

As seen in Table 2, the hiring require ments of employers are procedures such as teaching demonstration, interview, and test and documents such as transcript of records, application letter, curriculu $\mathrm{m} v$ itae, certificates of trainings and conferences attended, and lesson plan. The employer from DepEd referred to DepEd Order 7 series of 2015 which is a checklist of other requirements. In the said department order, the preferred skills are cookery, carpentry, dressmaking, indigenization, and experience as alternative learning system (ALS) teacher as specified in Department Order number 50, series of 2016.

In the Philippines, employers request applicants who pass the minimum qualifications and/or the initial interview to submit requirements.

Table 2. Hiring Requirements

\begin{tabular}{|l|l|}
\hline Requirements & Frequency \\
\hline Teaching demonstration & 13 \\
\hline Interview & 10 \\
\hline Skill test & 3 \\
\hline Checklist pertinent to DepEd Order 7 s. 2015 & 1 \\
\hline Transcript of record & 1 \\
\hline Application letter & 1 \\
\hline Curriculum vitae & 1 \\
\hline Training and conferences attended & 1 \\
\hline Lesson plan & 1 \\
\hline
\end{tabular}

Table 3 details the attributes of AUF alumni observed and named by the employers, including values, skills, knowledge and grades. Values top the attributes evident among AUF TE graduates followed by their skills then their specific knowledge.

Table 3. Attributes of AUF graduates

\begin{tabular}{|l|l|}
\hline Attributes & Frequency \\
\hline $\begin{array}{l}\text { Value laden (understanding, creative, pleasing, eager } \\
\text { to work, desirable, confident,resourceful, engaging, } \\
\text { collaborative, respectful, refined) }\end{array}$ & 12 \\
\hline Skills (communication, classroom management) & 12 \\
\hline $\begin{array}{l}\text { Knowledgeable (discipline, research, strategies, } \\
\text { relevant subjects) }\end{array}$ & 8 \\
\hline Earning good grades & 1 \\
\hline
\end{tabular}

\section{Discussion}

The knowledge and skills identified by the employers are integrated in the TE curricu lu m; hence, the transcript of records of applicants can initially reveal the extent of their knowledge as measured by grades. However, such knowledge must show and be highlighted during the hiring process. All of these knowledge-related requirements are 
aligned with the GAs professionally competent and lifelong learning.

Respondents also identified necessary skills such as good communication skills because a teacher constantly interacts with stakeholders such as parents, students, and other members of the school community. Two named the skill in managing and planning teaching since teachers plan and teach as their primary role. One specified the skill "using the computer" most likely because of automated systems (e.g., school information system) and information and communications technology (ICT) features being used in schools. While the first skill aligns with professional competence, the next connects directly to global oriented-ness. The study of Maynes and Hatt [8] arrived at similar results, particularly the ability to manage and plan teaching as desirable abilities.

Moreover, participants wish to see other work-related values which are associated with the attributes values oriented, ethically responsible, and critical and creative thinker. Participants also named other hiring qualifications which all link to the attribute professional competence.

Brewer, Kretchmar, Sondel, Ishmael, and Manfra [9] noted that some hiring committees have preferred graduates of certain schools. However, the respondents in the current study did not single out a particular preferred school but wrote "coming from a good school" which can be measured through accreditations, certifications and awards or distinctions, and even ranking of educational institutions. In place of the teaching experience which most applicants may not possess, hiring committees may look at grades especially if earned from a reputable school. In the Philippine context, both public (local and state colleges and universities) and private colleges and universities subject themselves to accreditation, hence giving notable advantage to their graduates.

In line, the results agree with some previous studies such as the paper of Awofala, Olabiyi, Ogunleye, Udeani, and Fatade [7]. More specifically, teachers need to develop their personal attributes, teaching skills, core, and process skills to be work-ready.

To screen participants, schools require the former documents and processes. Supporting the findings in this study, Whitworth, Deering, Jones, and Hardy [10] concluded that personal interview tops the considerations when hiring while demonstration teaching ranks second. In this study, however, teaching demonstration outnumbers interview. During interviews, the use of conceptual language (e.g., theories in education) is an evidence of actual ability to teach [8].

In general, ability to answer questions--usually about differentiated instruction, curriculum, concepts, content and mention of the importance of student engagement, the use of various resources, and the use of technology [8] - and communication skills are displayed through interviews [10]. Both interview and demonstration teaching require application of knowledge on both content and pedagogy.

Meanwhile, DepEd Order 7 series of 2015 summarizes the requirement and point system of the Department. Specifically, the applicant is rated based on Education (20 points), teaching experience (15), board examinations rating (15), specialized training and skills (10), interview (10), demonstration teaching (10), and communication skills (15). The require ments in the said order are similar to what the private sectors ask for; on the other hand, private schools may hire non-board passers or fresh graduates with the eventual requirement to pass.

It is noteworthy that one employer wants applicants who are experienced in research as she/he named "conference" as a requirement. In line, the students who presented research papers demonstrated more intellectual autonomy and were able to repurpose their work for presentation to a mu ltid isciplinary audience as co mpared with peers who did not [11]. Knowledge on research may also lead to research-based practices in the clas sroom.

The requirements of both public and private sectors coincide with the graduate attributes professional competence and globally oriented.

Meanwhile, graduate attributes are evidence that individuals are work-ready [12]. When asked what attributes are evident among graduates of AUF, respondents enumerated attributes pertinent to knowledge, skills, and values. The results confirm the findings of Hinchliffe and Jolly [13] that value, intellect, social engagement and performance are important to employers.

Participants also named their expectations which are unmet by applicants from AUF. These expectations are values, training, and specialized skills. The values confidence and loyalty are specifically desired as shown in Table 1 while the needed training is on classroom manage ment and on the art of questioning. The specialized skills also appear as desired training in Table 1. Hence, AUF graduates may improve some values and skills which employers look for through the emphasis of such in the curriculum.

The hiring requirements are also congruent with the domains in PPST particularly content knowledge and pedagogy, learning environment, diversity of learners, curriculum and planning, assessment and reporting, and community linkages and professional engagement. The AUF GAs also align well with PPST; specifically values-oriented and community linkages and professional linkages; socially and ethically responsible and community linkages and personal growth and professional development and learning environment; professionally competent and critical and creative thinker and content knowledge and pedagogy; lifelong learner and globally oriented and personal growth and professional development. Hence, there are traces of international standards in both AUF GAs and hiring requirements.

TEIs, both private and public, are therefore invited to make conscious and informed decisions about further 
ensuring the alignment among their own GAs, hiring require ments and even PPST and their curriculum content, co-curricu lar activities, pedagogies and the nature and use of learning spaces [3].

Studies such as this one also encourage the representatives of the labor market to be more active and more enthusiastic about discussions with the universities about their future employees' training. Overall, what is required in a workforce is not the acquisition of KSVs per se, but the capability to make an engagement through which KSVs are connected as a whole [14] and how the KSVs are actually translated and enhance outstanding teaching performance when already employed.

\section{Conclusions}

The researchers learned that the hiring-related requirements of employers among AUF teacher graduates are aligned with the graduate attributes of AUF. Thus, the graduate attributes are timely and relevant and the TE programs are responsive to the needs of the employers. The TE graduates possess the desired traits and job ready but may still improve training and specialized skills.

The researchers recommend a needs-responsive plan on training to be calendared, a review of curriculum to give emphasis to points raised by employers, a wider scope of respondents including other degree programs and locale, particularly region wide, and a triangulation of perspectives including graduates and parents. While this study described AUF graduates collectively, their performance as individual faculty members may be highlighted in future studies.

\section{REFERENCES}

1. N. Bacani. CHED lists in-demand, priority college courses until 2018. The Philippine Star. Philippines, 2014.

2. F. J. Espeso, D. Nakpil, A. C. Tapao. Teacher education regains popularity. Vera Files. Online available from http://verafiles.org/articles/teacher-edu cation-regains-pop ularity, 2017.

3. J. Hill, H. Walkington, D. France. Graduate attributes: implications for higher education practice and policy, Journal of Geography in Higher Education, Vol.40, No.2, 155-163, 2016.

4. C. Hughes, S. Barrie. Influences on the assessment of graduate attributes in higher education, Assessment \& Evaluation in Higher Education, Vol.35, No.3, 325-334, 2010.

5. F. A. Albalooshi. Graduate Attributes for Higher Education and Their Development in Bahrain, International Education Studies, Vol.6, No.9, 23-30, 2013.

6. R. Spronken-Smith, A. McLean, N. Smith, C. Bond, M.
Jenkins, S. Marshall, S. Frielick. A toolkit to implement graduate attributes in geography Curricula, Journal of Geography in Higher Education, Vol. 40, No. 2, 254-266, 2016.

7. A. O. Awofala, O. S. Olabiyi, A. Ogunleye, U. N. Udeani, A. O. Fatade. School Administrators Perceptions of the Employability of Preservice Science, Technology, and Mathematics Teachers through Teaching Practice in Nigeria, International Journal of Research in Education and Science, Vol.3, No.1, 42-55, 2017.

8. N. Maynes, B. E. Hatt. Hiring and supporting new teachers who focus on students' learning, Canadian Journal of Educational Administration and Policy, No.44, 1-37, 2013.

9. T. J. Brewer, K. Kretchmar, B. Sondel, S. Ishmael, M. M. Manfra. Teach for America's Preferential Treatment: School District Contracts, Hiring Decisions, and Employment Practices, Education Policy Analysis Archives, Vol.24, No.15, 1-38, 2016.

10. J. Whitworth, S. Deering, T. Jones, S. Hardy. Hiring Quality Teachers: The Devil is in the Details, Professional Educator, Vol.40, No.1, 1-14, 2016.

11. J. Hill, H. Walkington. Developing graduate attributes through participation in undergraduate research conferences, Journal of Geography in Higher Education, Vol. 40, No. 2, 222-237, 2016.

12. K. Howells, N. Fitzallen, C. Adams.. Using Assessment to Develop Social Responsibility as a Graduate Attribute in Teacher Education, Australian Journal of Teacher Education, Vol. 41, No. 6, 52-67, 2016.

13. G. W. Hinchliffe, A. Jolly. Graduate identity and employ ability, British Educational Research Journal, Vol. 37, No. 4, 63-584, 2011.

14. Y. Su, L. Feng. Assessing graduate attributes for employability in the context of lifelong learning: The holistic approach, US-China Education Review, Vol. 5, No. 11, 1-10, 2008.

15. Department of Education-Teacher Education Council. Philippine Professional Standards for Teachers. 2017. 